\title{
Semejanzas entre procedimientos de Erwin Piscator y procesos de creación dramatúrgica actorales
}

\section{Similarities between Erwin Piscator procedures and acting dramaturgical creation processes}

\author{
Elisa Martins Lucas \\ Doutora e Mestre em Ciências do Espetáculo pela Universidade de Sevilha (Espanha) - \\ elisa.lucas97@gmail.com - orcid.org/0000-0003-2569-4873
}

\section{Resumo}

El artículo presenta un análisis de los procedimientos adoptados por el director alemán Erwin Piscator en los procesos adaptativos de las piezas Rasputín (1927) y Las Aventuras del Buen Soldado Schweik (1927) y los compara con algunos procesos de creación dramatúrgica contemporáneos. Los procedimientos utilizados por Erwin Piscator pueden ser considerados como precursores del proceso de creación dramatúrgica actoral desarrollado por actores contemporáneos, pero desde el punto de vista del director.

Palavras-chave: Teatro alemán. Piscator, Erwin, 1893-1966.Teatro (Literatura) - Técnica. Creación (literaria, artística, etc.) en el arte.

\section{Abstract}

This essay presents an analysis of the procedures adopted by the german director Erwin Piscator in the adaptive processes of the plays Rasputín (1927) and The Adventures of the Good Soldier Schweik (1927). The procedures employed by Erwin Piscator can be regarded as pioneers of the actor's dramaturgical creation processes developed by contemporaneous authors, but from the director's viewpoint.

Keywords: German drama. Piscator, Erwin, 1893-1966. Drama-Technique. Creation (Literary, artistic, etc.) in art 


\section{INTRODUCCIÓN}

Las transformaciones ocurridas en la práctica teatral a partir de finales del siglo XX cambiaron el modo como se ve y se construye la dramaturgia en la contemporaneidad. El concepto de dramaturgia se ha ampliado y ya no se centra exclusivamente en el oficio de escribir textos dramáticos por medio de postulados literarios y normas compositivas, pasando a incluir otros elementos del espectáculo. Si antes el texto, cuya autoría pertenecía únicamente al dramaturgo(a) (que dominaba su forma y contenido), era considerado el dispositivo más importante del teatro, determinando la puesta en escena en un proceso de transposición realizado por el director(a); con el paso del tiempo, dicha realidad ha cambiado y se puede percibir la interferencia del actor/actriz en la creación dramatúrgica. Muchos(as) artistas, solos(as) o en sus colectivos, además de desarrollar metodologías de interpretación y dirección, piensan dramatúrgicamente sus creaciones en espectáculos resultantes de procedimientos prácticos en que texto y escena son construidos a través de procesos colaborativos, de creación colectiva, de adaptación de obras literarias, con o sin la interferencia de un(a) escritor(a) profesional.

En este contexto nace el proceso de creación dramatúrgica actoral, definido como el conjunto de “[...] procesos de creación donde el actor actúa también como autor, interfiriendo en la creación dramatúrgica de la obra" (LUCAS, 2016, p. 28). Dichas prácticas invierten el orden convencional del teatro: en vez de partir de un texto para construir el personaje, actores/actrices y directores(as), trabajando prácticamente, parten de un personaje, de un tema o de una situación para construir el texto dramatúrgico y el espectáculo a través de la exploración máxima de diferentes recursos (objetos, músicas, filmes, pinturas, libros, etc.) y metodologías diversas (según la trayectoria de cada artista), siempre buscando sorprenderse a sí mismos y a su público y comunicarse creativamente.

Lejos de ser algo caprichoso y momentáneo, dicho proceso es una tendencia que se venía fraguando desde al menos la época de Erwin Piscator (1893-1966), director alemán representante del Teatro Épico ${ }^{1}$, en los años veinte del pasado siglo. Se llegó a esa constatación durante la escritura de la tesis doctoral Lo Profano y lo Sagrado en el proceso de creación dramatúrgica del actor a partir

\footnotetext{
${ }^{1}$ Género teatral que surge en los años veinte, adoptado también por Brecht y que, según Pavis (2017, p. 130) recupera y enfatiza la intervención de un narrador y supera la dramaturgia aristotélica fundada en la tensión dramática, el conflicto y la progresión regular de la acción.
} 
del personaje de María Magdalena. Interrelación entre Teoría y Praxis Escénica² (2016) realizada en el Doctorado en Ciencias del Espectáculo de la Universidad de Sevilla, bajo la dirección de la Doctora María Concepción Pérez Pérez. El objetivo general de la tesis era sistematizar una metodología del proceso de creación dramatúrgica actoral y, al observar procesos de creación contemporáneos se percibió semejanzas con procedimientos adoptados por Piscator. A continuación, se presenta un análisis de aspectos de procedimientos adoptados por Piscator en las obras Rasputín (1927) y Las Aventuras del Buen Soldado Schweik (1927) que pueden ser reconocidos como precursores del proceso de creación dramatúrgica actoral, y se los compara con obras contemporáneas desarrolladas por actores-dramaturgos y actrices-dramaturgas.

\section{LA CONSTRUCCIÓN DRAMATÚRGICA DE ERWIN PISCATOR}

El teatro realizado por Piscator nació como herramienta de transformación ante la urgencia de un arte de protesta cuya materia prima eran sus referencias (históricas, documentales, fílmicas, literarias; también, la realidad de la I Guerra Mundial con todas sus víctimas, daños, cambios, realidades y causas), más sus ideas y propuestas escénicas a partir de todo el material que iba acumulando. A ello hay que añadir una gran experimentación en los medios técnicos (luces, niveles de escenografía, música, uso del cine dentro del teatro, canciones, proyecciones, maquinaria moderna, escenarios móviles, etc.). Pretendía construir una dramaturgia político-sociológica basada en un nuevo punto de vista en donde los nuevos medios escénicos desarrollasen un papel fundamental y para ello buscaba enlazarles, especialmente la escenografía, para que incidieran en el efecto final de sus adaptaciones. Deseaba derrumbar la cuarta pared y establecer un acuerdo entre teatro y realidad, sin el estilo rígido e inmutable impuesto por la escena a la caja. Diseñaba sus espectáculos habiendo previamente llevado a cabo una profunda investigación documental, informativa y escénica. El texto se relacionaba con otros elementos de la puesta en escena, al mismo tiempo en que todos los elementos presentes en la puesta ocupaban función dramatúrgica, característica que fue perfeccionando a cada montaje. Para Campo (2004, p. 115) en la práctica escénica de Piscator no hay ninguna simpleza. Las exigencias del trabajo escénico se desarrollan de modo novedoso partiendo de connotaciones prácticas: “[...] la problemática que será abordada en la

\footnotetext{
${ }^{2}$ Investigación realizada con Beca de la Coordinación de Perfeccionamiento de Personal de Nivel Superior -CAPES - Brasil.
} 
sala, la obra que será representada, el autor al que se encargará la composición, o cuya composición se tomará por base $[\ldots] "$.

El director alemán tenía una visión bastante pesimista de la escena de su época. El teatro y su “pesada maquinaria dramática y técnica" (PISCATOR, 1976, p. 156) ya no interesaban más, una vez que los periódicos y el cine comunicaban al público con más realidad y novedad. Tampoco se identificaba con la dramaturgia que su tiempo le ofrecía. Salvo pocas excepciones, ni la manera en que se presentaba el teatro (cuarta pared, barrera entre ficción y realidad, interpretación con sentimentalismo exacerbado), ni la obra dramática en sí (tanto en forma como en contenidos abstractos, liricos, centralizados en el héroe, mezclados y con predominante factor psicológico individual de los personajes) les consideraba apropiados para los problemas e inquietudes de su tiempo.

Piscator interfería en la creación dramatúrgica (que muchas veces se daba a través de la adaptación), construyendo el texto juntamente con la puesta en escena, a partir de una serie de referencias y elementos de la propia obra, en un formato que él propio definió como teatro de la totalidad (PAVIS, 2017, p. 395), refiriéndose a un teatro de objetividad crítica y análisis casi científica, cuya construcción era concebida por el juego teatral, dejando de captar trozos de la realidad y pasando a desear la realidad total. Un tipo de teatro que, en lugar de sentimientos y conflictos personales expuestos, presentaba imparcialmente procesos sociales en una simultaneidad de sucesos históricos, combinación de acciones y reacciones sociales y políticas que podrían ser representadas a la vez, solicitando al público que tomase una decisión, y no más que disfrutase de la obra.

Con el objetivo de construir una especie de drama histórico, Piscator pasó a desarrollar una escritura teatral fundada en la mediación del dramaturg ${ }^{3}$ y en la adaptación de autores y textos clásicos alemanes y universales, recurso utilizado tradicionalmente por el teatro y más modernamente por el cine. Dar vida y cuerpo a los conflictos de una novela y, sobre todo, compartirla con el espectador, se convertía en un recurso creativo de proporciones sorprendentes que le facilitaría la comunicación con la platea.

\footnotetext{
${ }^{3}$ Término alemán utilizado por Patrice Pavis (2017, p. 117) para designar el consejero literario y teatral vinculado a una compañía, a un director o a un responsable de la preparación de un espectáculo. El alemán distingue, a diferencia del francés y del castellano, el Dramatiker, el que escribe obras, del Dramaturg, que prepara su interpretación y su realizaçón escénicas.
} 
En las novelas, Piscator encontró el contenido de lo que quería comunicar: intrigas, temas y personajes complejos, que permitían mayor acercamiento e identificación del público con la obra. La transposición escénica de clásicos le ofrecía posibilidades lúdicas y novedosas, tornando a una gran novela todavía aún más asombrosa, entusiasmando al público y haciendo con que el original diera la impresión de un boceto (PISCATOR, 1964, p. 362). No le importaba que la acción cultivada en el público tuviese un origen épico o dramático, desde que el teatro lograse cumplir la misión de hacer con que el ser humano fuese tocado y se viese reflejado, una vez que consideraba como gran finalidad del Teatro Épico acercar el espectador del drama, activando su mirada (PISCATOR, 1964, p. 362).

Debido a los apuros que tuvo al adaptar, Piscator pasó a construir la dramaturgia juntamente con los demás elementos de la puesta en escena (escenografía, iluminación, cine, etc.), de forma que estos elementos pasaron a colaborar con el texto en una dinámica que hacía con que la puesta en escena naciese como resultado de tal combinación. El texto ahora era complementado por luces, escenografía, movimiento e imagen, es decir, lo escénico pasaba a complementar la literatura.

\section{SEMEJANZAS ENTRE PROCEDIMIENTOS DE ERWIN PISCATOR Y PROCESOS DE CREACIÓN DRAMATÚRGICA ACTORALES}

Piscator era consciente de las necesidades del oficio teatral: profesionalización, relación viva con el espectador(a) y dominio de los medios técnicos (escénicos, arquitectónicos, cinematográficos y musicales). Dichos elementos también se tienen en cuenta en procesos de creación dramatúrgica actorales, aunque ni siempre se exploran los medios técnicos, ya que se tratan de procesos fundamentados en las herramientas expresivas del actor/actriz y en su relación con el/la espectador(a).

Diversos procedimientos adoptados por Piscator guardan cierta semejanza con procesos de creación dramatúrgica actorales, entre los cuales se incluyen investigación documental, función dramatúrgica de la escenografía, rigurosa funcionalidad escenográfica, utilización de guiones coreográficos o esquema de movimientos, autonomía creativa y labor experimental.

\subsection{AMPLIO ESTUDIO DOCUMENTAL, INFORMATIVO Y ESCÉNICO}


En sus procesos adaptativos, Piscator recogía a una investigación histórica, bibliográfica, documental y fílmica. El amplio estudio realizado, que iba más allá de la obra que pretendía escenificar, además de enriquecer el proceso de adaptación, fortalecía los estímulos para la puesta en escena a partir de metáforas e imágenes visuales. Piscator se utilizó de este recurso en el montaje Rasputín (1927), de Alexéi Nikoláievich Tolstói (1883-1945) en lo cual utilizó 18 fuentes (PISCATOR, 1976, p. 212-213). A través de dicha investigación, formó un calendario (PISCATOR, 1976, p.214), en cuyo resumen cronológico determinó puntos en que los acontecimientos políticos se cruzaban con los hechos de la obra. Tales puntos, considerados como "ejes de la acción", fueron intercalados con nuevas escenas que contenían una miscelánea de referencias históricas y políticas. Como resultado fueron añadidas diecinueve escenas a las ocho escenas originarias, de forma que el texto completo de la obra abarcó el período histórico de comienzos de 1915 hasta octubre de 1917 y el texto original funcionó como telón de fondo donde el interés era el asunto histórico-político y no el destino privado del protagonista Rasputín. Tal forma de intervenir en la adaptación de forma esquemática puede resultar en una herramienta útil en procesos de creación dramatúrgica actorales que pretendan adaptar clásicos literarios.

Dicha característica de amplio estudio se encuentra en procesos de creación dramatúrgica actorales contemporáneos, donde se suele apreciar, tanto en procesos colectivos como individuales, una detallada investigación que reúne materiales relacionados con el tema que va a ser tratado. En la obra española De no llegar a tiempo4 (Sevilla, 2014), de la Compañía Maribel Ramos "La Zambra”, fue utilizado procedimiento semejante. El espectáculo, acuñado por sus creadores de una comedia flamenca, llevó a la escena el personaje histórico de Carmencita Dauset, bailaora almeriense, llamada la Perla Sevillana, que en 1894 apareció en una grabación de Thomas Edison, posiblemente el primer registro del baile andaluz. La dramaturgia fue creada por la bailaora de Flamenco Maribel Ramos y por el director teatral Miguel Cegarra a partir de la anecdótica situación vivida por el personaje, que, a punto de salir a escena, comprobó que los músicos que la debían acompañar, debido a retrasos ferroviarios, no habían llegado a tiempo para la función. Además de incluir la anécdota biográfica, la dramaturgia se construyó a partir de un estudio histórico del personaje. Cegarra y Ramos organizaron un guion con los datos históricos que pretendían citar de Carmencita Dauset y a partir de

${ }^{4}$ Para mayores informaciones, véase: https://issuu.com/danzapuntoesinaem/docs/1.dosier._de_no_llegar_a_tiempo 
improvisaciones crearon nuevos textos y añadieron nuevas escenas a dicho guion. Ya para la creación dramatúrgica de A Dama dos Evangelhos ${ }^{5}$ (2012), que recría poéticamente la trayectoria de la figura bíblico-literaria-legendaria de María Magdalena, la actriz/dramaturga Elisa Lucas, del Grupo Capitu (Porto Alegre-Brasil) hizo un amplio estudio del personaje que incluyó:

[...] trabajo de campo en la Semana Santa de Sevilla, visita y registro fotográfico a la Parroise de la Madeleine (Paris), consulta a fuentes bibliográficas, folclóricas y pictóricas, procedentes de diferentes tradiciones, que sirvieron para hacer el embasamiento de la selección de situaciones del personaje y definir los objetivos que lo mismo pretendería alcanzar a lo largo de la dramaturgia a ser creada. (LUCAS, 2019b, p.157)

\subsection{RELACIONES ENTRE DRAMATURGIA Y ELEMENTOS ESCENOGRÁFICOS Y ESCÉNICOS}

A partir de sus lecturas de los recuerdos de Maurice Paléologue (1859-1944), Piscator se quedó con la imagen metafórica del globo terráqueo, sobre el cual se desarrollaban los acontecimientos. Dicha imagen le permitía construir la obra Rasputín (1927) bajo dos perspectivas: la escénica, a través de una estructura escenográfica esférica de hierro que posibilitaba dos niveles de actuación, además del escenario; y la dramática, que figurativamente extendería el destino del personaje de Rasputín, transformando la obra en una visión del destino de toda Europa. Partiendo de estos dos puntos de vista, empezó a trabajar en la concepción de una escenografía que mostraría la guerra y sus efectos de forma plástica, contribuyendo a contar la historia (Fig. 1).

Así, en Rasputín, la escenografía contribuía a expresar la idea del director. La metáfora teatral se expresaba por la estructura del montaje del texto/espectáculo y la funcionalidad mecánica de la escenografía. El montaje con escenas intercaladas se adecuaba al escenario esférico, uniendo una finalidad práctica a la significación simbólica. Además, la estructura escenográfica permitía, sin necesidad de telón, múltiples y rápidos cambios, sirviendo para las proyecciones de películas que indicaban el contexto histórico de la acción escénica y su espacio dramático. Esa es otra característica que se encuentra en procesos de creación dramatúrgica actorales. Sus puestas en escena suelen presentar transposiciones poéticas que se muestran por medio de elementos escénicos o escenográficos, ya que los/las actores/actrices se sirven de metáforas como estímulos, tanto en la creación del texto, como durante los procesos de montaje.

\footnotetext{
${ }^{5}$ Para mayores informaciones, véase: https://elisalucasteatroblog.wordpress.com/a-dama-dos-evangelhos/
} 
Figura 1: Escenografía de Rasputín (de la izquierda hacia la derecha): Estructura, parte del globo descubierto donde

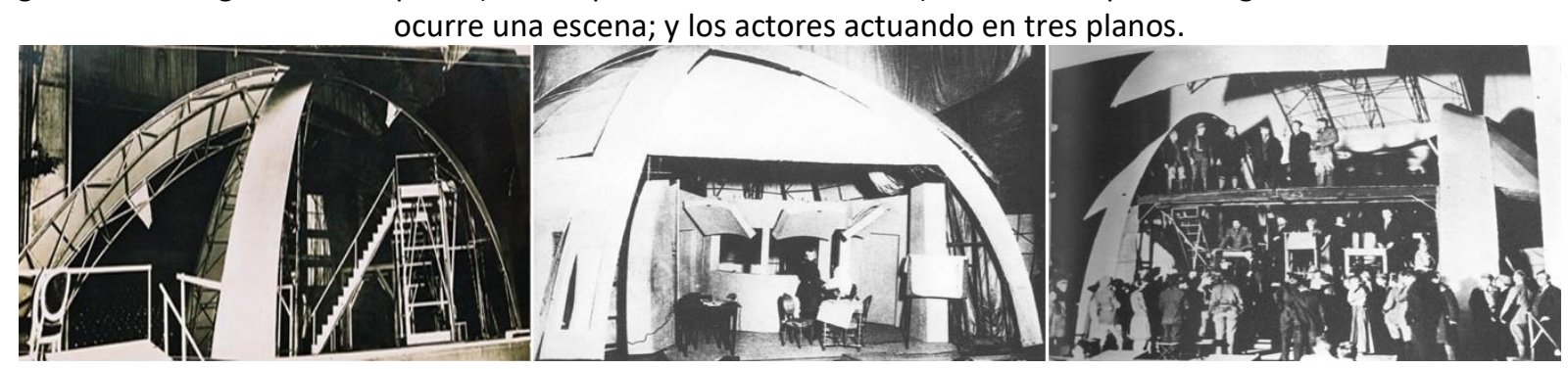

Fuente: Archivo de la autora.

De la misma forma, la funcionalidad escenográfica que caracteriza a los montajes de Piscator, también tiene cierta relación con procesos de creación dramatúrgica actorales, pero en una escala menor, ya que las puestas en escena resultantes de dichos procesos suelen ser más intimistas y sencillas, aunque también el actor/actriz se puede valer de distintos elementos para que le ayuden en la construcción de la narrativa. Eso ocurría en Rasputín cuya escenografía, alejándose de cualquier carácter decorativo, presentaba una rigurosa utilidad.

Rigurosa utilidad en la escenografía se presenta en el monólogo Confesso que Capitu6 (2004), del Grupo Capitu (Porto Alegre - Brasil), con dramaturgia de Elisa Lucas y Roberto Birindelli. El proceso de creación dramatúrgica actoral de esta obra partió del personaje de Capitu, de la novela Dom Casmurro (1899), de Machado de Assis. En Dom Casmurro, el autor/narrador Bento Santiago dice escribir la novela para "anudar las dos puntas de mi vida y recuperar la adolescencia en la vejez" (ASSIS, 2008, p. 34), es decir, narrar su historia le hace revivir los grandes momentos de su vida y reflexionar sobre ellos; para la creación del monólogo se partió de dicha proposición. Por eso, las acciones del personaje de Capitu han sido construidas a partir de hilos, representando esas puntas, las tramas de la vida del personaje, que van envolviendo visualmente el imaginario del espectador. En efecto, una parte del escenario está ocupada por hilos, que van configurando el espacio escénico y con los cuales la actriz interactúa a lo largo de la obra (Fig. 2).

\footnotetext{
${ }^{6}$ Para mayores informaciones, véase: https://elisalucasteatroblog.wordpress.com/espetaculo-confesso-que-capitu/
} 
Figura 2: Parte de la escenografía de Confesso que Capitu está compuesta por hilos en una metáfora de Dom Casmurro. En las imágenes: Elisa Lucas.



Fotos: Mira Gonçalves y Kiran Federico León.

Recursos sencillos construyen la puesta en escena y todos los elementos dispuestos en la escenografía contribuyen para contar la historia. En el escenario, además de los hilos, una mesa, una silla y un ordenador. A modo de vestuario, prendas femeninas caracterizan momentos distintos en la vida del personaje Capitu (Fig. 3).

Figura3: Recursos sencillos componen la puesta en escena de Confesso que Capitu.

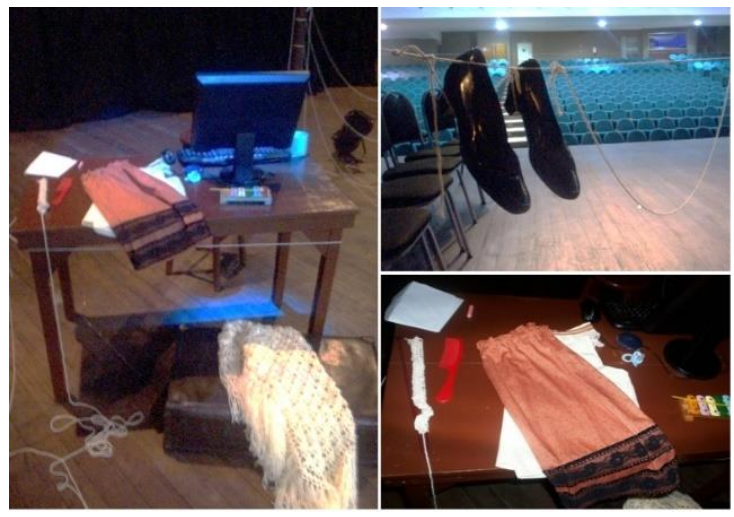

Fotos: Elisa Lucas. 
Otro ejemplo en que los elementos escénicos contribuyen a expresar la idea de la obra se puede observar en el premiado espectáculo Ensaio Hamet ${ }^{7}$ (2004) del grupo Cia dos Atores (Rio de Janeiro - Brasil), considerado un "desmontaje" del clásico de Shakespeare. Todos los elementos escénicos de la puesta en escena son simbólicos y aluden a la obra Hamlet (Fig. 4). Los actores incluso llegan a utilizar carne cruda, como metáfora de la matanza que se lleva a cabo en la obra.

Figura.4 - Bel Garcia interpreta Ofelia en dos escenas de Ensaio.Hamlet. En la foto de la izquierda, enseña las cartas que Hamlet le ha enviado. En la foto de la derecha, con una gran botella de vino hace alusión al ahogamiento.
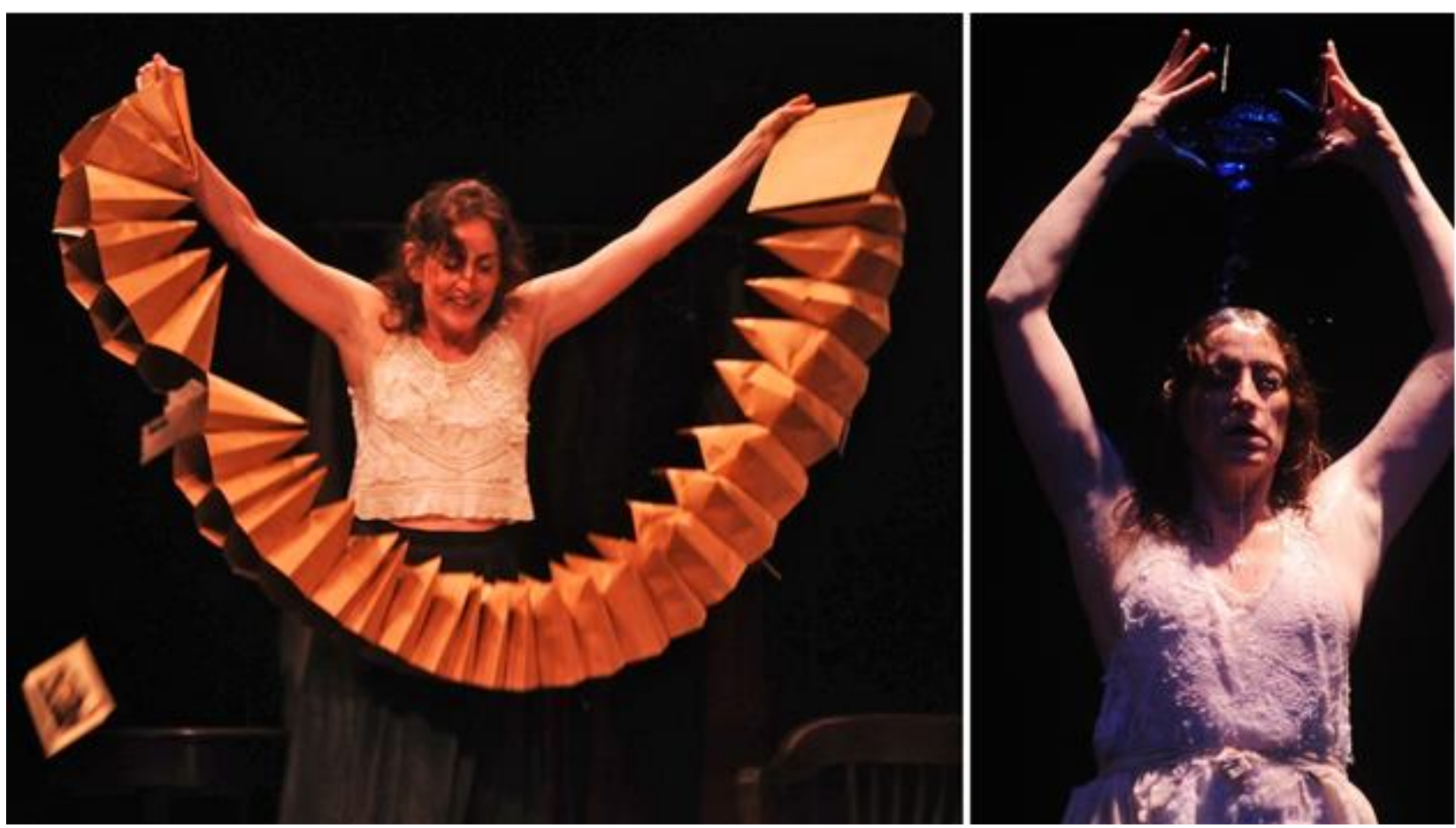

Fotos: Bob Sousa. Fuente: Acervo Bob Sousa.

Ya en el proceso de adaptación de Las Aventuras del Buen Soldado Schweik (1927), debido a las dificultades encontradas en la adaptación, Piscator primero determinó la forma de la escenografía y el medio escénico correspondiente, para después trabajar en el texto. En la adaptación, además de Max Brod y Hans Reimann, colaboraron Bertold Brecht, Felix Gasbarra y Leo Lania. Los elementos de la novela parecían hacer inviable una adaptación a la escena, ya que la obra era un conjunto de anécdotas y aventuras sin conexión, y no presentaban unidad. Tampoco tenía final, una vez que el

\footnotetext{
${ }^{7}$ Para mayores informaciones, véase: https://enciclopedia.itaucultural.org.br/evento457664/ensaiohamlet
} 
autor había muerto antes de concluirla. El protagonista estaba definido desde el principio, pero no sufría ninguna evolución durante la obra.

La adaptación presentó muchos problemas, llegando a tener una primera versión donde el protagonista, atendiendo a los mejores pasajes del texto original, salía de la novela para ser colocado en medio de una acción inventada, lo que hizo que perdiera atmósfera propia. Piscator renunció a la dramatización del personaje y, en lugar de una obra dramática sobre Schweik, se presentó una parte íntegra de la propia novela. A partir de ahí, la siguiente dificultad fue la forma del escenario, lo que hizo que Piscator concluyera que el desarrollo épico necesitaba nuevos medios técnicos. Gasbarra (1928, citado en PISCATOR, 1976, p. 246-247) describe el proceso de montaje, que aquí se presenta sintetizado, y el modo como se resolvieron las cuestiones dramatúrgicas con la escenografía y la utilización de proyecciones.

La primera dificultad fue el escenario inmóvil, que reducía los sucesos del libro a escenas aisladas. El problema fue resuelto cuando Piscator convirtió el escenario fijo en un suelo rodante (una banda sin fin), medio escénico que correspondía al desarrollo épico de la novela. Luego, los adaptadores eligieron las escenas más dramáticas y adaptaron el texto a la escena. A continuación, distribuyeron el contenido basándose en la novela y buscaron dar "vida escénica al mundo que rodea a Schweik y que tanto influye en él", cuestión también resuelta por Piscator, mediante la película en forma de dibujo. A través del diálogo, mitad escénico y mitad textual, se resolvieron cuestiones técnicas y dramáticas. Tras determinar la forma del escenario y el medio escénico adecuado, el trabajo de la dramaturgia consistió en reducir las características literarias, haciendo recortes considerables y modificando la distribución del material, aunque respetando el texto original (PISCATOR, 1976, p. 247).

Otra vez Piscator utiliza herramientas que más tarde podrá emplear un(a) actor/actriz en procesos de creación dramatúrgica. El/la actor/actriz-dramaturgo(a) puede, antes de crear su texto, elegir un objeto escénico o una estructura que traduzca de forma metafórica lo que quiere enfocar en la dramaturgia, experimentar posibilidades de movimiento y de juego escénico, e incluso limitaciones con dicha estructura, y después crear el texto motivado por dichas posibilidades y limitaciones. Proceso semejante ocurrió durante en la creación de la obra Código de Barra ${ }^{8}$ (Porto

\footnotetext{
${ }^{8}$ Para mayores informaciones, véase: https://www.youtube.com/watch?v=xGfSazu8018
} 
Alegre, 2005), con texto y actuación de Carina Sehn. La actriz/dramaturga ya tenía parte del texto hecho a partir de una dramaturgia que pretendía abordar la personalidad de una persona sociópata, explorando temas como paranoia, miedo y soledad. Buscando una estética minimalista, Senh optó por una estructura escenográfica cuadrada formada por cuatro persianas (Fig. 5) que limitase su espacio de actuación y mostrase cómo se sentía el personaje, presionado y solo, dentro de su piso, escuchando a los vecinos.

Figura.5: Carina Senh en Código de Barra. Estructura formada por cuatro persianas.

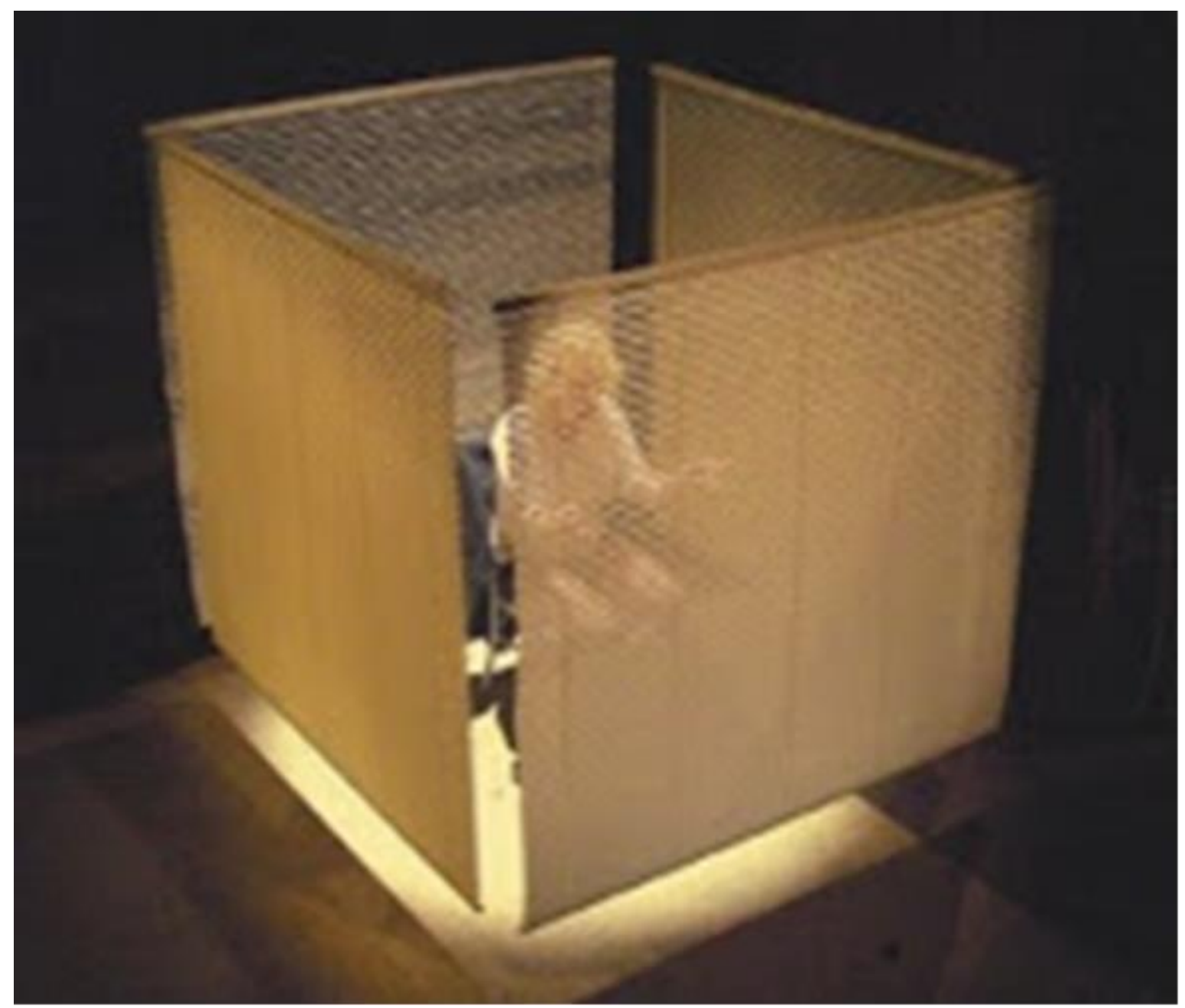

Foto: Guto Mahals.

A partir de la escenografía, la actriz/dramaturga creó nuevos textos sobre las posibilidades de acciones y movimientos que dicha estructura le proporcionaba: espiar, abrir y cerrar la persiana, esconderse, vigilar, mirar por la ventana. La escenografía contorneaba la silueta de la actriz, 
dibujando su figura y los espectadores aparecían como voyeurs ${ }^{9}$, al quedar como si estuvieran espiando al personaje, ya que durante toda la obra permanecían cerradas las persianas.

\title{
3.3 UTILIZACIÓN DE GUIONES COREOGRÁFICOS O ESQUEMAS DE MOVIMIENTOS
}

En un episodio de Las Aventuras del Buen Soldado Schweik (1927), Piscator (1976, p. 243) se utilizó de un esquema de movimiento escénico, que funcionaba a modo de guion coreográfico, con indicaciones de entradas y salidas de personajes, elementos escenográficos e indicaciones de diálogos:

\begin{abstract}
Acto II, escena 2a (Anábasis): Banda 1ạ moviéndose de derecha a izquierda: Schweik marcha, de izquierda a derecha, cantando. En la banda 1a (de derecha a izquierda) entra, parada: una vieja. Encuentro. Banda 1aㅡ se detiene: Diálogo hasta: <<...regimiento, ien marcha!>> Banda 1a (de derecha a izquierda): Continúa la marcha de Schweik. La vieja sale, parada. En la banda 1a entran: Postes de Kilómetros, árboles, el letrero: Pueblo de Maltschin. En la banda 2a (de derecha a izquierda) entra: una taberna. Escena hasta: «<...al regimiento con la mayor rapidez>>. Banda 1a y $2 \underline{a}$ corren de derecha a izquierda: La taberna sale. Schweik marcha. En la banda 2a entra: Una pila de heno (roncan durante 08 segundos). Escena hasta $<<\ldots$ si no hubieran desertado $>$. Banda $1 \underline{a}$ corre (medio minuto). Banda $2^{\underline{a}}$ corre, justamente con la $1^{\underline{a}}$ de la izquierda a derecha.
\end{abstract}

Esquemas de movimientos son también utilizados en dramaturgias resultantes de procesos de creación dramatúrgica actorales. Como se observa en el texto de Histórias de Uma Mala Só10, estrenado en 2009 y publicado en 2018, de Elisa Lucas (Porto Alegre - Brasil). Creado a partir de improvisaciones teatrales, presenta en sus acotaciones sugerencias de soluciones escénicas a modo de indicaciones de acciones, movimientos coreografiados, onomatopeyas, manipulación de objetos, escenografías, así como diversas sonoridades:

NARRADORA: Atención Señores Pasajeros, ¡El viaje va a comenzar! (Deja la maleta en el piso, en la diagonal derecha del escenario. Saca del bolsillo un Guía de Viaje imaginario y comienza a leer). Según el Diccionario Universal de la Lengua Portuguesa, viaje es: (Coreografía y ejecución de sonidos de acuerdo con cada acción que va describiendo) Marcha o cualquier otro modo de desplazamiento más o menos lejos, hecho en: Rá-ma-ma-man... Automóvil; Piu-iíííííí Tren; Vfuuuuuuuuuu: ¡Avión! O navío. Ommmmmmm

\footnotetext{
${ }^{9}$ Mirones en francés.

${ }^{10}$ Para mayores informaciones, véase: https://elisalucasteatroblog.wordpress.com/historias-de-uma-mala-so/
} 
(En el momento del navío, se vira de espaldas, da adiós con un lienzo que saca del bolsillo y se vira). (LUCAS, 2018, pág. 17) $)^{11}$

\subsection{AUTONOMÍA CREATIVA}

Aunque Piscator no haya producido una dramaturgia propia, actuaba con tanta autonomía con la obra como si fuera el autor de los textos que llevaba a escena. Su labor en el montaje iba más allá de lo que sería el conocimiento de un director de escena. Durante sus montajes, manuscrito, música y escena, eran creados juntamente con el texto de forma paralela, mientras Piscator ejercía a la vez las distintas funciones de autor, director, músico, escenógrafo y actor (PISCATOR, 1976, p. 77). En este proceso, desarrolló nuevos procesos de escritura teatral y presentó ideas que son determinantes para la transformación de la dramaturgia contemporánea. Según Hernando (1994, p. 81), el concepto Teatro Político de Piscator marca un corte epistemológico y diseña una problemática científica para el teatro:

[...] una práctica específica (el teatro total, la distanciación, los niveles escenográficos) que conduce a la apropiación cognitiva de lo real (diremos que una apropiación específica en relación con el conocimiento) mediante un trabajo de transformación (la moderna dramaturgia) que se ejerce sobre una materia prima (conjunto de ideas, imágenes y representaciones sociales) y que después de ser trabajadas (proceso de producción) dan forma a un ver, un hacernos sentir la realidad.

Dicha autonomía creativa se observa en el proceso de creación del espectáculo unipersonal Olympia $^{12}$ (2001), con Ângela Mourão, del Teatro Andante, de Belo Horizonte-Brasil. Aunque la dramaturgia había sido creada por Guiomar de Grammont, el director Marcelo Bones destaca la interferencia muy particular de la actriz, que cambió toda la concepción del espectáculo como si fuera "una creación de autor" (OLIVETTO; CARREIRA, 2006, p. 3). En este caso, la actriz, aunque no fuera la creadora del texto, tenía claro lo que pretendía comunicar a su público.

\footnotetext{
${ }^{11}$ NARRADORA: Atentos Senhores Passageiros, a Viagem vai começar! (Deixa a mala no chão, na diagonal direita do palco e vai para o centro. Tira do bolso um Guia de Viagem imaginário e começa a ler). Segundo o Dicionário Universal da Língua Portuguesa, viagem é: (Coreografia e execução de sons de acordo com cada ação que vai descrevendo) Caminhadă ou qualquer outro modo de deslocamento mais ou menos distante feito em: Rá-ma-ma-ma-man... Automóvel; ChicFuuuuu...Trem: Piu-ííííííí! Avião: Vfuuuuuuuuuu! Ou navio. Ommmmmmmm (No momento do navio, atriz vira-se de costas, dá adeus com um lenço que tira do bolso). (Traducción nuestra).

12 Para mayores informaciones, véase: https://www.teatroandante.com.br/olympia
} 


\subsection{LABOR EXPERIMENTAL}

Piscator consideraba su teatro una labor experimental: “[...] era este teatro un experimento, un salto en un campo desconocido, [...] un experimento en cuanto al público, en cuanto al drama, en cuanto al montaje [...]" (PISCATOR, 1976, p. 165). Esta característica igualmente se presenta en procesos de creación dramatúrgica actorales, como se puede observar en la obra Carta de um Pirata. Uma comedia inconformada ${ }^{13}$ (2003), en que el actor/dramaturgo y también director Vinicius Piedade (São Paulo), teniendo por base la experimentación escénica, tras haber estudiado a fondo la historia de los piratas y enumerado las cuestiones que le interesaba abordar, creó una dramaturgia a partir de algo tan sencillo como una carta que un pirata escribe a su madre, y luego montó un espectáculo a base de improvisaciones, con texto, y con movimientos de Mímica Corporal y Danza Contemporánea (LUCAS, 2019a, p. 113).

\section{CONCLUSIONES}

Los procedimientos adoptados por Piscator en las obras Rasputín (1927) y Las Aventuras del Buen Soldado Schweik (1927) presentan semejanzas con procesos de creación dramatúrgica actorales contemporáneos, de forma que se puede concluir que el referido director inició en el pasado una especie de proceso de creación dramatúrgica del director. Lo que Piscator consideraba la misión del director(a), funciona hoy como objetivo de muchos actores y actrices en el escenario: dar visión a la ficción. El drama vivo y pujante de Piscator se realiza ahora mediante los movimientos y silencios del actor/actriz en el escenario, por medio de técnicas interpretativas y compositivas que nos remiten a sus conceptos, no en cuanto a forma, sino en cuanto a sus principios: autonomía creativa, conocimiento de lo que se pretende comunicar, relación del texto con todos los demás elementos de la puesta en escena, exploración de medios y también de lenguajes. Un(a) actor/actriz se puede valer de los procedimientos utilizados por Piscator en la construcción de su dramaturgia.

\section{REFERÊNCIAS}

ASSIS, M. Don Casmurro. Brasília: Fundação Alexandre de Gusmão, 2008.

\footnotetext{
${ }^{13}$ Para mayores informaciones, véase: https://www.viniciuspiedade.com.br/carta-de-um-pirata
} 
CAMPO, J. P. G. El Conflicto y la Escena: Arte y Política en Piscator. In: Revista Riff-Raff. Zaragoza, $n$. 26, p. 107-115, 2004.

HERNANDO, C. V. Erwin Piscator: Problemática y corte epistemológico. In: ADE teatro: Revista de la Asociación de Directores de Escena de España, Madri, n. 34, p. 81, 82, 83, feb. 1994.

LUCAS, E.M. Histórias de uma mala só. Porto Alegre: EDIPUCRS, 2018. v. 1

LUCAS, E. M. Lo Profano y lo Sagrado en el proceso de creación dramatúrgica del actor a partir del personaje de María Magdalena: Interrelación entre teoría y praxis escénica. 2016. Tesis (Doctorado en Ciencias del Espectáculo) - Programa de Doctorado en Ciencias del Espectáculo, Facultad de Filología, Universidad de Sevilla, Sevilla, 2016.

LUCAS, E. M. O Processo de criação dramatúrgica do ator: Percursos investigativos na prática teatral. In: Fritsch. V. H. de C. (org.). Dramaturgia: poéticas do moderno e do contemporâneo. Rio de Janeiro: Bonecker, 2019a. v. 1, p. 103-119.

LUCAS, E. M. Un experimento de proceso de creación dramatúrgica del actor a partir del personaje de María Magdalena. DAPESQUISA, v. 14, n. 23, p. 155-175, ago. 2019b.

OLIVETTO, D.; CARREIRA, A. L. A. N. Processos Criativos do Teatro de Grupo: Investigando Diálogos e Papéis do Ator. In: JORNADA DE PESQUISA CEART, 2.; SEMINÁRIO DE INICIAÇÃO CIENTÍFICA DA UDESC,16., 2006. Anais[...] Florianópolis, 2006.

PAVIS, P. Dicionário da performance e do teatro contemporâneo. São Paulo: Perspectiva, 2017.

PISCATOR, E. A Adaptação de Romances à Cena (1956). In: REDONDO JR et al. O Teatro e sua Estética. Lisboa: Arcádia, 1964. p .353-363

PISCATOR, E. Teatro Político. Madrid: Editorial Ayuso, 1976.

SOUSA, B. Ensaio Hamlet. Website Biblioteca do Instituto de Artes - Digital UNESP. Acervo Bob Sousa. Disponível em: http://acervodigital.unesp.br/handle/123456789/65697. Acesso em: 30 set. 2019. 